\title{
Surveillance of Influenza A/California/H1N1 in Dnipropetrovsk, Ukraine
}

\author{
Oleksandr Shtepa*, Valentyna Rezvykh and Maryna Bredykhina
}

State Institution Dnipropetrovsk Oblast Laboratory Center of the Ministry of Health of Ukraine, Dnipro, Ukraine

\section{Introduction}

Ukraine's ability to respond to the spread of viruses that cause pandemics and reduce economic losses from influenza, can be strengthened only in the presence of a developed surveillance network including the monitoring of virus circulation in humans. Specialists of Dnipropetrovsk Oblast have great experience in virological surveillance on the circulation of influenza virus A/California/H1N1 and timely determination of the etiology of outbreaks caused by the virus.

\section{Methods}

Laboratory diagnostics of influenza was performed using serological methods, PCR, and virological studies in the cell culture. During the last seven epidemic seasons, including the flu pandemic of 2009-2010, most of samples came from four health-care facilities of Dnipropetrovsk, which were determined as basic hospitals for the sentinel center. Patients with severe acute respiratory infections (SARI) were examined. Nasopharyngeal washouts and swabs were collected into cryo-tubes with a transport medium. The samples were stored at hospitals in Dewar flasks.

The delivery of the samples to the laboratory was performed according to cold-chain rules. After sample preparation stage, the samples were tested for the presence of influenza A/B virus RNA by PCR using Bio-Rad CFX-96 cycler and the following commercial test-kits AmpliSens ${ }^{\circledR}$ Influenza virus A/B-FL, AmpliSens ${ }^{\circledR}$ Influenza virus $\mathrm{A} / \mathrm{H} 1$-swine, and AmpliSens ${ }^{\circledR}$ Influenza virus A-type-FL.

All positive samples with detected RNA of influenza virus A/H1-swine were tested using MDSK cell cultures (Canine Kidney Epithelial Cells). Flu viruses caused cytopathic changes in the cell cultures in the form of poppy-sand-like degeneracy not earlier than in 72 hours after the infection of the cells followed by cell monolayer fragmentation.

Fig. 1 MDSK cell culture

Fig. 2 MDSK cell culture 72 hours after infection with influenza virus $A$ (H1N1)

Express immunochromatic tests «Cito test influenza $\mathrm{A}+\mathrm{B}$ » or agglutination test (AT) using erythrocyte suspension of human 0 (I) group blood were used for the determination of haemagglutinating agents.

\section{Results}

During the seven epidemic seasons, 5,467 people were examined for flu and acute respiratory viral infections. During the swine flu pandemic in 2009-2010, 1,217 severely ill patients were tested. Positive results were found in $50 \%$ of cases (607 persons). From those, pandemic influenza virus (RNA of influenza A/H1-swine virus) was detected in $100 \%$ of positive cases.

Fig.3 Data on the determined pandemic flu virus strains (RNA of influenza A/H1-swine virus) using PCR during epidemiological seasons from 2009 to 2016 in Dnipropetrovsk Oblast, Ukraine

Frequency of pandemic influenza virus detection declined to zero in the following epidemic seasons (2010-2011 and 2011-2012). However, incidence of the virus variant (influenza A/H1-swine) began to grow slowly during the last four epidemic flu seasons from separate cases (6 in 2012-2013, 1 in 2012-2013) to 26 cases in 2014-2015. During the last epidemic season (2015-2016), the number of pandemic influenza cases increased dramatically to 166 , accounting $29 \%$ of all examined persons.

Fig. 4 Results of isolation of pandemic strains of influenza viruses in cell culture MDSK flu epidemic seasons from 2009-2010 to 2015-2016 in Dnipropetrovsk Oblast, Ukraine

Most of the virus isolates were sent for confirmation and further identification to the Ukrainian Center for Influenza and to the world influenza centers (Atlanta, USA and London, UK) in order to support Ukraine's participation in the worldwide pandemic influenza surveillance. The world flu centers confirmed the isolates to be influenza virus strain A/California/(H1N1)/07/2009.

\section{Conclusions}

1. Circulation of the pandemic type of influenza virus A/California/ (H1N1)/ 07/2009 among the population of Dnipropetrovsk oblast is of sporadic character.

2. The return of the virus $\mathrm{A} / \mathrm{California} /(\mathrm{H} 1 \mathrm{~N} 1) / 07 / 2009$ after the 2009-2010 pandemic occurred during the last 2015-2016 epidemic season.

3. Application of PCR can significantly shorten the examination of patients with severe course of influenza, but cannot help with virus isolation.

4. The use of express immunoassay tests accelerates the identification of viruses isolates.

5. The employment MDSK cell culture for influenza virus isolation allows obtaining of a spectrum of influenza strains circulating during an epidemic period including the strain A/California/(H1N1)/07/2009.

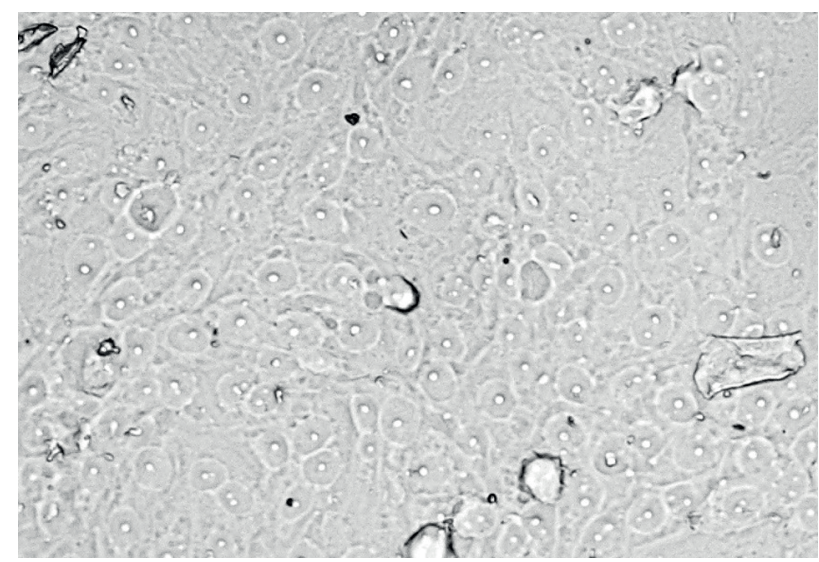



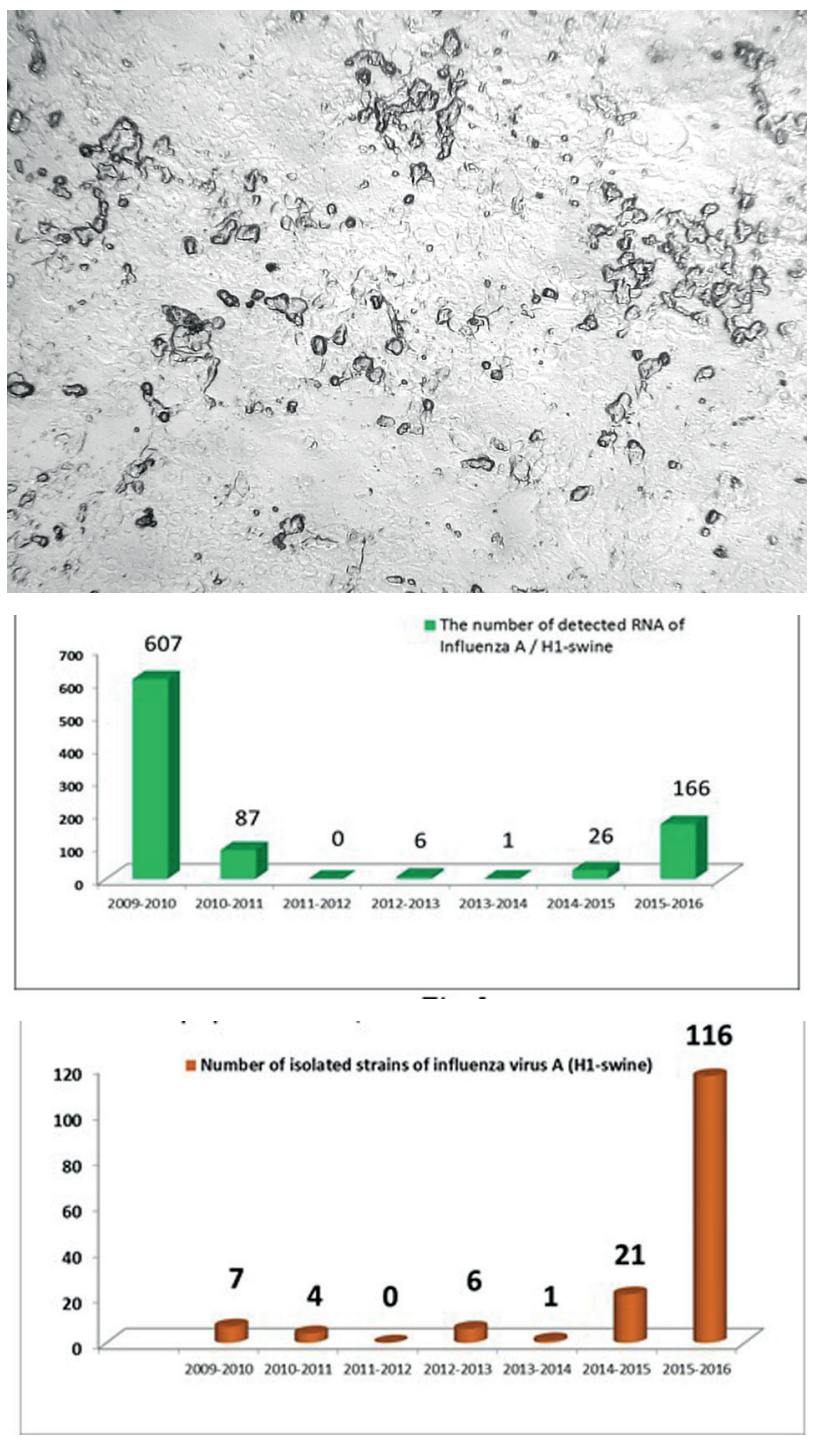

\section{Keywords}

Influenza; Surveillance; PCR; Virology; MDSK

\section{*Oleksandr Shtepa}

E-mail: shtepaap@gmail.com 